\title{
CORRESPONDENCE
}

\section{Isolation of 'free-living' amoebae causing human disease}

The review by Szénási and her co-authors [1] was useful, particularly the information on the new primary amoebic meningoencephalitis isolate from the Philippines ('Naegleria philippinarum'), and the possibility of a similar isolate from a swimming pool fed by a geothermal spring in Szeged, Hungary. However, I was surprised that reference to Balamuthia mandrillaris, an important cause of fatal human and animal brain infections [2] was omitted. This omission, also important because some infections previously thought to be caused by acanthamoebae, including one cited by the authors [3], were due to that leptomyxa-like amoeba [4]. B. mandillaris does not grow on the bacterial lawns used to isolate other 'free-living' amoebae from clinical specimens and environmental samples. B. mandrillaris does consume acanthamoebae [4], and might therefore be isolated on plates inoculated with environmental samples if food protozoa for it were also present. Specimens from suspected cases should be inoculated into tissue cultures. This is information that needs to be widely known, if more isolates of balamuthia are to be obtained.

The relationships between legionellae and free-living amoebae are varied and complex, but the notion of legionellae as 'endosymbionts of amoebae' [1] is not how I originally viewed the relationship between them [5]. At a low temperature a legionella may be consumed with little effect on the amoeba, but at a higher temperature it may multiply rapidly and reduce the amoeba to a bag full of highly motile legionellae. Thus, at low temperatures the legionellae may be food for amoebae, but at a higher temperature destroy them [6]. The same legionella may not infect other amoebae, or only rare obviously infected amoebae are seen. If an amoeba was to take in a legionella, but not utilise it as food, and the legionella was unable to multiply significantly, it could be considered an endosymbiont in that amoeba. If conditions were to change, such that weak amoebae succumbed to legionella infection, the fittest would survive. If the legionellae eventually released from the infected weak amoebae then readily infected and destroyed competing amoebae, or ciliates, or both, in the same habitat, then the legionella could be regarded as an aggressive endosymbiont for the first amoeba, and a pathogen for its competitors.

Sarcobium lyticum (L2), referred to by the authors as a bacterial endosymbiont of amoebae, has always been regarded as a parasite of amoebae, it is now in the genus Legionella as L. lytica [7]. Incidentally strain L2, isolated from Polish soil in 1954, is now the oldest viable isolate of a legionella from the environment.

Some legionellae are pathogenic for man, other bacteria pathogenic or symbiotic for amoebae may also be pathogenic for man, e.g., certain chlamydialike cocci [8], and strain LLAP-3, a L. lytica-like bacillus isolated from a case of pneumonia [7]. Therefore, amoebae are not only important as pathogens in their own right, but also as hosts for bacteria causing human disease.

T. J. Rowbotham, Leeds Public Health Laboratory, Bridle Path, York Road, Leeds LS15 7TR

\section{References}

1. Szénási Z, Endo T, Yagita K, Nagy E. Isolation, identification and increasing importance of 'free-living' amoebae causing human disease. J Med Microbiol 1998; 47: 5-16.

2. Visvesvara GS, Schuster FL, Martinez AJ. Balamuthia mandrillaris, N.G., N.Sp., agent of amebic meningoencephalitis in humans and other animals. J Eukaryot Microbiol 1993; 40: 504-514.

3. Anzil AP, Rao C, Wrzolek MA, Visvesvara GS, Sher JH, Kozlowski PB. Amebic meningoencephalitis in a patient with AIDS caused by a newly recognized opportunistic pathogen, Leptomyxid ameba. Arch Pathol Lab Med 1991; 115: 21-25.

4. Visvesvara GS, Martinez AJ, Schuster FL et al. Leptomyxid ameba, a new agent of amebic meningoencephalitis in humans and animals. J Clin Microbiol 1990; 28: 2750-2756.

5. Rowbotham TJ. Preliminary report on the pathogenicity of Legionella pneumophila for freshwater and soil amoebae. J Clin Pathol 1980; 33: 1179-1183.

6. Fallon RJ, Rowbotham TJ. Microbiological investigations into an outbreak of Pontiac fever due to Legionella micdadei associated with use of a whirlpool. J Clin Pathol 1990; 43: 479-483.

7. Adeleke A, Pruckler J, Benson R, Rowbotham T, Halablab M, Fields B. Legionella-like amebal pathogens - phylogenetic status and possible role in respiratory disease. Emerg Infect Dis 1996; 2: $225-230$

8. Birtles RJ, Rowbotham TJ, Storey C, Marrie TJ, Raoult D. Chlamydia-like obligate parasite of free-living amoebae. Lancet 1997; 349: $925-926$. 